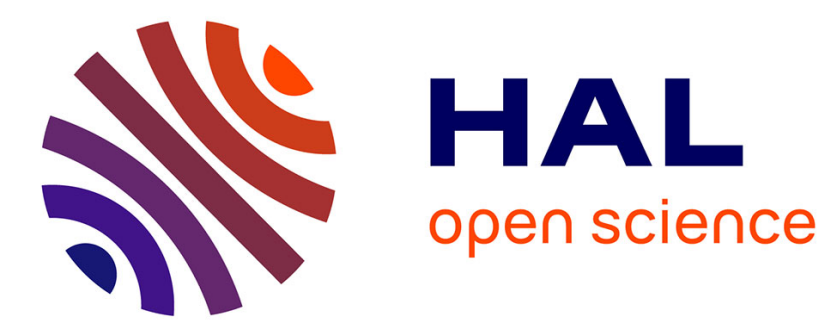

\title{
Towards the three-dimensional FE analysis of rapid prototyping tools for sheet metal stamping process
}

M. Oudjene, Luc Penazzi, Jean-Louis Batoz

\section{To cite this version:}

M. Oudjene, Luc Penazzi, Jean-Louis Batoz. Towards the three-dimensional FE analysis of rapid prototyping tools for sheet metal stamping process. Finite Elements in Analysis and Design, 2007, 43 (8), pp.611-619. 10.1016/j.finel.2006.12.012 . hal-01717322

\section{HAL Id: hal-01717322 \\ https://hal.science/hal-01717322}

Submitted on 7 Nov 2018

HAL is a multi-disciplinary open access archive for the deposit and dissemination of scientific research documents, whether they are published or not. The documents may come from teaching and research institutions in France or abroad, or from public or private research centers.
L'archive ouverte pluridisciplinaire HAL, est destinée au dépôt et à la diffusion de documents scientifiques de niveau recherche, publiés ou non, émanant des établissements d'enseignement et de recherche français ou étrangers, des laboratoires publics ou privés. 


\title{
Towards the three-dimensional FE analysis of rapid prototyping tools for sheet metal stamping process
}

\author{
M. Oudjene ${ }^{\mathrm{a}, *}$, L. Penazzi ${ }^{\mathrm{b}}$, J.-L. Batoz ${ }^{\mathrm{c}}$ \\ ${ }^{\mathrm{a}}$ ERMeP, GIP-InSIC, 27 rue d'Hellieule, 88100 Saint-Dié-des-Vosges, France \\ ${ }^{\mathrm{b}}$ CROMeP, Ecole des Mines d'Albi-Carmaux, 81013 Albi Cedex 9, France \\ ${ }^{\mathrm{c}}$ Université de Technologie de Compiégne, 60205 Compiégne Cedex, France
}

\begin{abstract}
For low volume production or for rapid prototyping, sheet metal stamping tools can be made by an assemblage of steel sheets or layers and joined by several techniques (such as screws, bolts, brazing, adhesive). However, an important problem in the design and the production of such tools is their mechanical behaviour, in particular the strength of joining techniques which is crucial in the aim of achieving the high required reliability of tools. If tools mechanical behaviour can be mastered and accurately predicted this can increase the tools life duration and be more beneficial for the manufacturing community. In order to properly predict the mechanical behaviour of tools, numerical simulation of stamping taking into account, elastic deformation of tools within a coupled FE analysis is needed. However, simulation results show that the effort and computational times required for such a coupled simulation, in particular in a general three-dimensional (3D) case, could be prohibitive and unrealistic. In this paper, the authors proposed and developed a numerical procedure in two steps, which has the advantage of decoupling the simulation of the blank forming and the stress analysis of the elastic tools. Numerical application is presented for a layered stamping punch, based on the Stratoconception ${ }^{\circledR}$ rapid prototyping process, joined by screws in addition to an epoxy adhesive. The results are focussed on the screws behaviour, showing the potential interest of the developed procedure and numerical modelling technologies in designing layered tools joined by screws.
\end{abstract}

Keywords: FEM; Stamping process; Contact forces; Layered tooling; Rapid prototyping; Joining

\section{Introduction}

Sheet metal stamping process is among the oldest and most widely used industrial manufacturing process. The production of high quality parts with low cost is the ultimate goal for the manufacturing industry. On the other hand, the tools play a crucial role and the global cost of a stamped part is highly influenced by the cost of the tools, depending on the production volume. Therefore, new technologies, based on rapid prototyping techniques, have been continuously developed and evaluated in order to reduce cost and manufacturing delays of tools. In the last decade, several developments on rapid stamping tools, in particular those based on the assemblage of steel sheets

\footnotetext{
* Corresponding author. Tel.: +33 329421821; fax: +33329421825.

E-mail address: mourad.oudjene@insic.fr (M. Oudjene).
}

and joined by screws (or bolts), have been undertaken. Their production and their use on pressforming, to produce stamped parts, have been successfully explored [1-9]. None of these works, however, have examined the mechanical behaviour of the tools, which is vital in the aim of achieving high strength of tools, in particular the joining technique. In addition, the published papers and reports showed that the research performed to date on layered tools has been oriented only towards the problem of their rapid and flexible production [6]. Thus, prototyping tools have been designed and manufactured based only on guess and simple practical rules of thumb. At present, a number of complexities related in particular to the joining by screws are still not fully understood or not modelled. The mechanical strength of layered tools is closely related to the strength of the joining technique used. It is then of primary importance to understand the relation between the applied loads (stamping forces) and the given behaviour of screws. 
The evaluation of the strength of layered tools needs an evaluation of the stresses (and strains) induced in the tools during the stamping operation. However, those stresses are seldom computed in practice if not ignored in most of the to date stamping simulations. For accurate stress analysis of stamping tools, it would be necessary to take into account their elastic deformation during analysis within a coupled stamping simulation. However, previous work $[10,12]$ showed that the effort and computational times required for such a coupled simulation, in particular in a general three-dimensional (3D) case, could be prohibitive and unacceptable (strong practical difficulties are involved).

FE analysis of stamping tools taking into account their elastic deformation during analysis have been conducted in relation with the wear behaviour $[11,12,14,15]$ or stress analysis $[10,12-15,17]$. However, the limited number of works dealing with the behaviour of tools is mostly dealing with 2D situations (plane strain, axisymmetry).

In this paper, the authors proposed and developed a numerical simplified procedure, in two steps, for the 3D stress analysis of sheet metal stamping tools (layered or not). That procedure has the advantage to avoid the strong practical difficulties involved in a coupled stamping simulation by considering the elasticity of tools. It is based on the assumption that the contact forces acting on the rigid tools during stamping operation are almost identical to those acting on the elastic tools (standard steel tools). Thus, it exploits the knowledge of the distribution of the contact forces acting on the rigid tools to study, separately, the behaviour of elastic tools within a linear elastic analysis, by assuming the distribution of the contact forces as static external load.

First, the paper presents a series of stamping simulations taking into account elastic deformation of tools in order to show the validity of the assumption made on the contact forces, i.e. the stamping process contact forces results are the same between rigid and elastic tools. After that, the developed procedure is applied to study the 3D mechanical behaviour of a layered stamping punch joined by screws and adhesive. Both stress and strain developed in the layered punch have been investigated in previous work [12] and it was found that the maximum amount of both equivalent von-Mises stress and elastic deformation developed in the punch are still much lower than the yield point for the steel material used for the punch. Thus, we focussed in this study on the screws behaviour, which is of extreme importance for the strength and life duration of the layered punch. The results show several issues with the layered punch related to the joining by screws which need to be investigated more and mastered before it should be considered as suitable for production. Finally, some answers are established and some important considerations to improve the design of layered tools joined by screws are outlined.

\section{Coupling stamping FE analysis: adopted strategy}

The numerical simulation of the stamping process is extensively used for the analysis and the design of industrial parts to

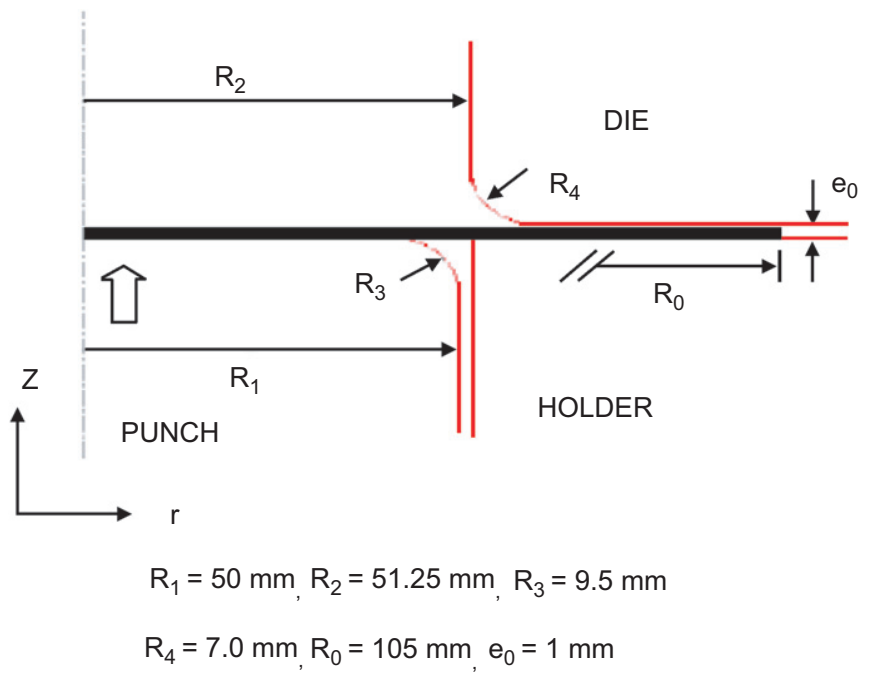

Fig. 1. Schematic illustration of the deep-drawing test [16].

avoid the long and expensive experimental tryout procedures. Thus, the previous stamping simulations have been concentrated exclusively on the workpiece behaviour mainly assuming rigid tools.

Two major numerical approaches are often used for the simulation of such problems: dynamic explicit and static implicit approaches. However, the implicit scheme is often limited by convergence problems, due to the contact conditions with friction.

Several numerical tests have been performed by the authors on some practical tools-part system where the behaviour of the tools has been evaluated regarding the intensity and the distribution of the stresses induced in the elastic tools, as well as the contact forces between the workpiece and the tools (rigid or elastic tools). The present section, deals with the results in the case of an axisymmetrical deep-drawing test. Both implicit and explicit codes are used, showing the limitations of explicit codes to deal with the full coupling between the blank forming and the stress analysis of elastic tools.

\subsection{Case study description}

The deep drawing of a cylindrical cup of Numisheet'2002 benchmark test [16], by considering the elasticity of the punch, was considered as the example of the application. In order to calibrate the numerical model with respect to the literature results, the simulation is, first, conducted classically by assuming a 3D situation with rigid tools as considered in [16], using ABAQUS/explicit finite element code. After that, coupling deep-drawing simulations were run by considering elastic deformation of the punch using ABAQUS/implicit (2D situation) and ABAQUS/explicit (3D situation). The quality of the simulation procedure was evaluated with regard to both the workpiece and the behaviour of the punch.

The deep-drawing parameters are shown in Fig. 1. All simulations have been carried out with a constant blankholder force of $70 \mathrm{kN}$ and punch stroke of $40 \mathrm{~mm}$. 


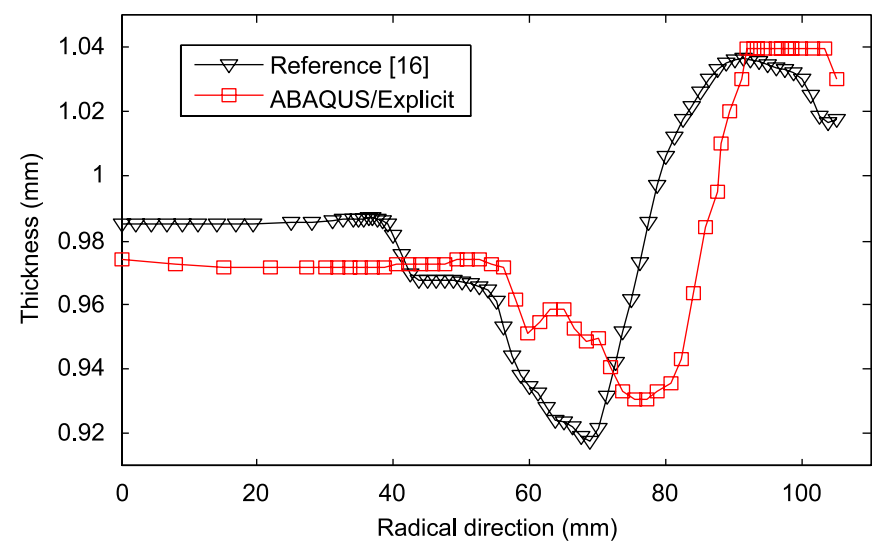

Fig. 2. Thickness distribution along the radial direction.

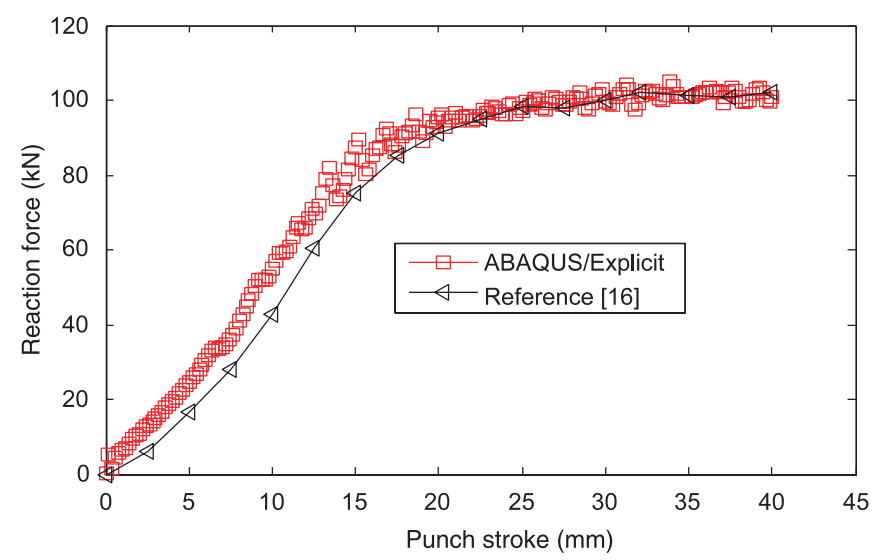

Fig. 3. Punch force-displacement curves.

Only one quarter of the model was considered as in $\mathrm{Nu}$ misheet'2002. The blank was modelled as an isotropic elastoplastic material with isotropic hardening characteristics given by Hollomon's model with the following material constants: $K=539 \mathrm{MPa}, n=0.27, E=210 \mathrm{GPa}$ and $v=0.3$. Coulomb frictional model was assumed with $\mu=0.04$ as considered in Numisheet'2002 [16].

\subsection{Classical stamping FE analysis with rigid tools}

A four-node shell element with reduced integration (element S4R of ABAQUS) is used to discrete a quarter of the initial blank involving in 1400 elements, while the other tools (punch, die, blankholder) were regarded as rigid (meshed with the rigid four-node element R3D4 of ABAQUS). A constant punch speed of $10 \mathrm{~m} / \mathrm{s}$ was adopted.

The thickness distribution along the radial direction is presented in Fig. 2, from which it is observed that the result obtained with ABAQUS/explicit is in agreement (maximum thickness deviation $0.01 \mathrm{~mm}$ ) with the literature one, but the thickness picks are not detected at the same distance from the centre (at $69 \mathrm{~mm}$ for the reference solution and at $76 \mathrm{~mm}$ for ABAQUS).

Furthermore, the punch reaction force is presented in Fig. 3 and it can be seen that the result is in good agreement with the literature one.

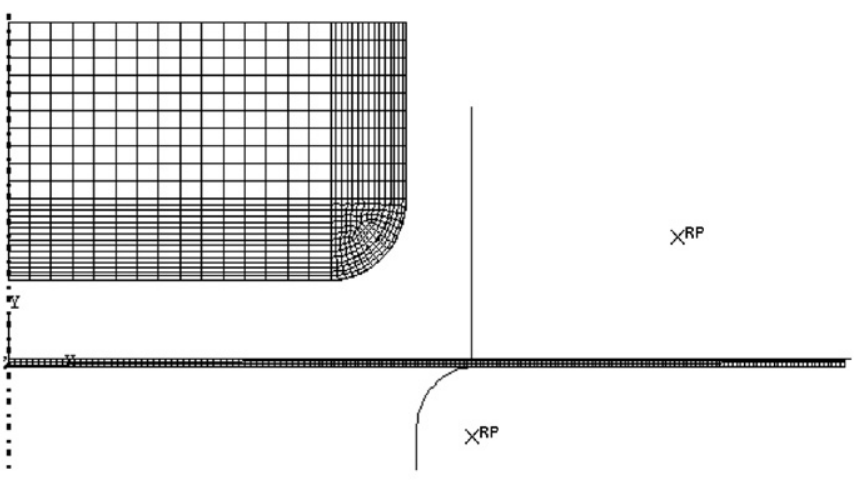

Fig. 4. 2D axisymmetric FE model with elastic punch.

\subsection{Stamping FE analysis with elastic punch}

To our best knowledge we do not have reference results for the punch behaviour. All the results available in the literature deal only with the stamped sheet. In order to compute an accurate solution (reference solution) regarding the punch behaviour, one wishes to deal with a 2D deep-drawing simulation using static implicit scheme (ABAQUS/implicit). Furthermore, we make a 3D deep-drawing simulation using dynamic explicit scheme to check that we obtain the same results regarding the punch behaviour as with a static implicit scheme.

\subsection{1. $2 D$ static implicit model}

The blank was modelled by 4 and 270 axisymmetric elements (denoted CAX4R in ABAQUS) in the thickness and radial directions, respectively.

The punch was modelled as an elastic and isotropic material with the following properties: $E=210 \mathrm{GPa}$ and $v=0.3$. A four-node element (CAX4 element of ABAQUS) was used to discrete the punch (Fig. 4), involving 821 elements.

By analysing the results, with regard to the workpiece final shape, it is found that the elastic deformations induced in the punch do not seem to have significant effects on both thickness and strains distributions.

The contact forces between the workpiece and the punch (rigid punch and elastic punch) have been evaluated regarding both the intensity and the distribution. Fig. 5 shows the contact forces acting on both the rigid and the elastic punch. It can be seen that the contact forces are almost identical, i.e. the elastic deformation induced in the punch are infinitesimal, so there is no effect on the contact forces.

In order to examine the distribution of the contact forces acting on the tools (rigid or elastic) during the stamping operation, see Fig. 6 which shows the distribution of the contact pressure as reaction forces applied to the deformed sheet. For the punch, it can be seen that the contact forces are mainly located along the punch radius and present two picks with a maximum amount value of $54 \mathrm{MPa}$. These two picks correspond to the beginning and the end of the contact between the deformed sheet and the punch radius. The result is qualitatively in good agreement with the literature $[3,12,14,15,17]$. 


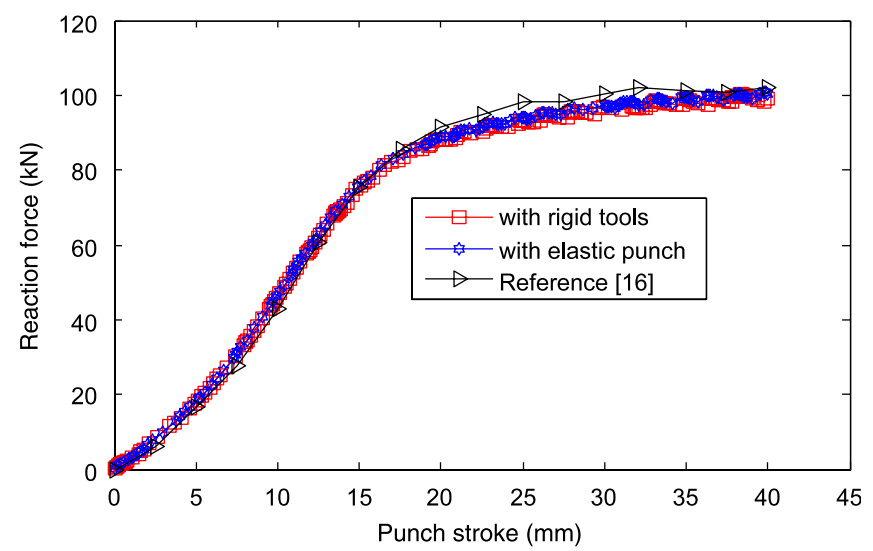

Fig. 5. Punch reaction force: comparison between rigid and elastic tools.

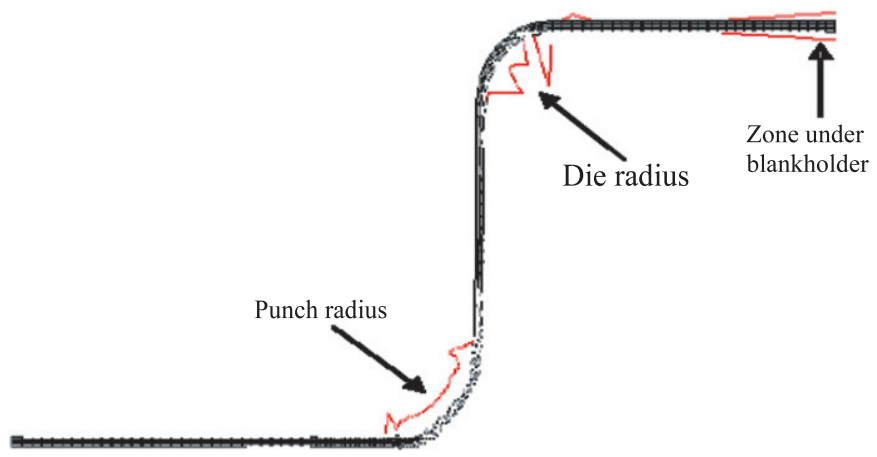

Fig. 6. Contact pressure distribution between the workpiece and the tools.
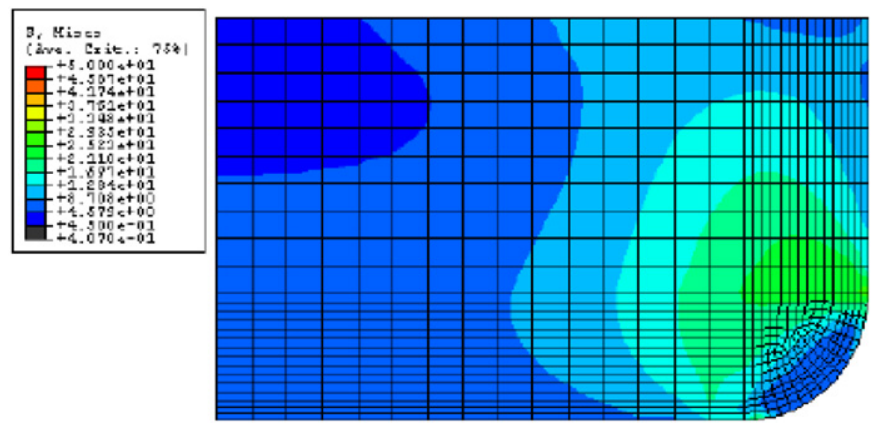

Fig. 7. Distribution of the von-Mises stress in the punch (reference solution).

By taking into account the elasticity of the punch, during the deep-drawing operation, it was also possible to obtain the distribution of the equivalent von-Mises stress (or elastic strain) developed in the punch (Fig. 7). The maximum amount of equivalent stress computed at the end of forming stage is around $35 \mathrm{MPa}$.

From the above results, it can be concluded that the elastic deformation of standard steel tools are infinitesimal and do not have significant influence on both the workpiece shape (strain, thickness distribution) and the contact forces.

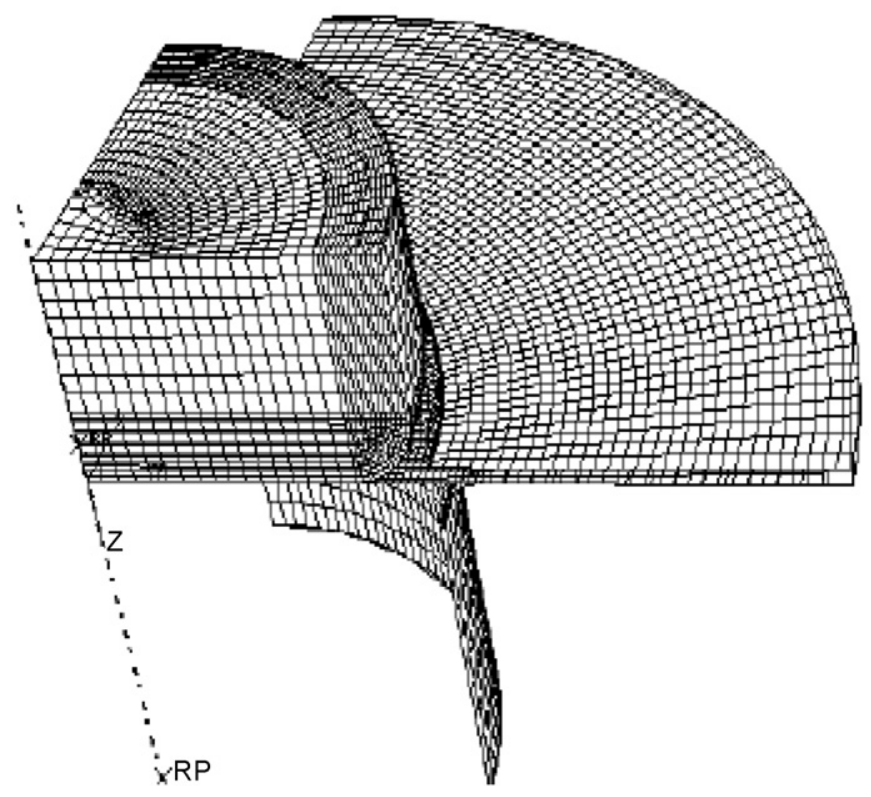

Fig. 8. 3D axisymmetric FE model with elastic punch.
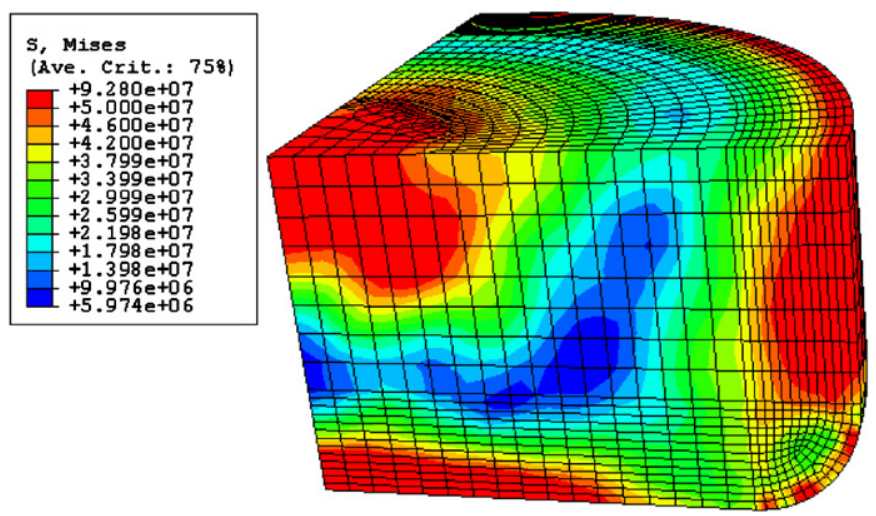

Fig. 9. Distribution of equivalent von-Mises stress in the elastic punch: case where $V_{p}=10 \mathrm{~m} / \mathrm{s}$.

\subsubsection{D dynamic explicit model}

The FE-simulation based on dynamic explicit scheme is standard in stamping simulation of parts with complex geometries. The objective of this model is to check that we obtain the same results regarding the punch behaviour as with a static implicit scheme.

The same mesh as in Section 2.2 was used for a quarter of the blank sheet (Fig. 8) while the quarter of the punch was meshed with 16469 eight-node brick elements with reduced integration (C3D8R element of ABAQUS).

The simulation was made by moving the punch download from its upper surface using a punch speed of $10 \mathrm{~m} / \mathrm{s}$.

The effect of the mesh quality in the punch on the results with regard to the stress distribution was already studied in [12]. Despite that, it was impossible to obtain a good estimation of the stress developed in the punch (Fig. 9), with a classical punch velocity of $10 \mathrm{~m} / \mathrm{s}$, compared to that obtained in the case of a static implicit scheme (Fig. 7). Moreover, the maximum amount of von-Mises stress developed in the punch is 

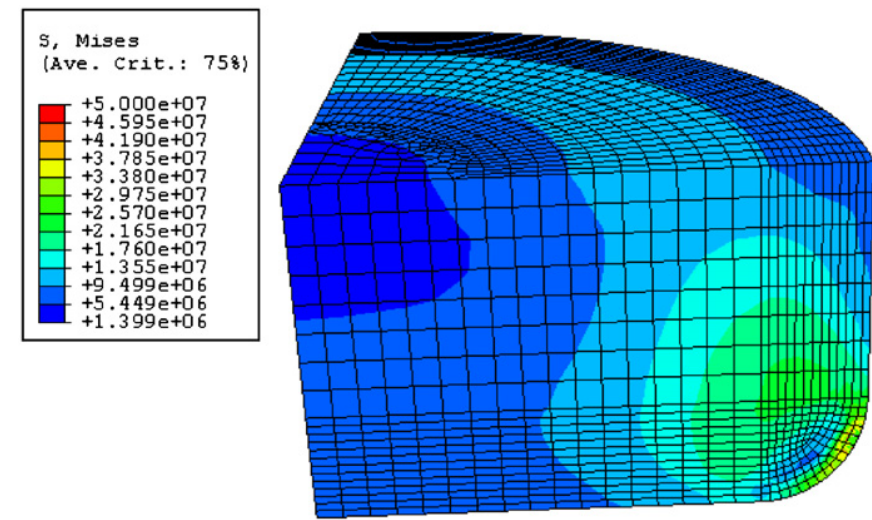

Fig. 10. Distribution of equivalent von-Mises stress in the elastic punch: case where $V_{p}=1 \mathrm{~m} / \mathrm{s}$.

Table 1

CPU times involved in the different simulations based on dynamic explicit scheme

\begin{tabular}{lll}
\hline 3D models (explicit) & \multicolumn{1}{c}{ CPU times } & \\
\cline { 2 - 3 } & $V_{p}=10 \mathrm{~m} / \mathrm{s}$ & $V_{p}=1 \mathrm{~m} / \mathrm{s}$ \\
\hline With rigid tools & $0 \mathrm{~h} 44 \mathrm{~min}$ & - \\
With elastic punch & $3 \mathrm{~h} 26 \mathrm{~min}$ & $33 \mathrm{~h} 4 \mathrm{~min}$ \\
\hline
\end{tabular}

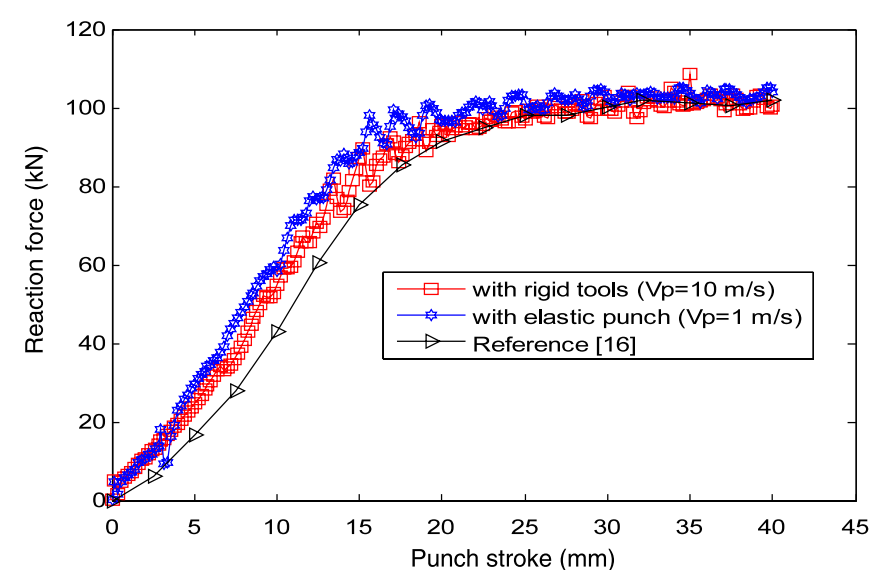

Fig. 11. Punch force-displacement curves: comparison between rigid and elastic tools (dynamic explicit scheme).

around $92 \mathrm{MPa}$. This is an important numerical result. In addition, the computed contact forces (punch reaction force curves) are strongly irregular.

However, with the decrease of the punch velocity from 10 to $1 \mathrm{~m} / \mathrm{s}$, it became possible to obtain a fairly good estimation of the stress distribution in the punch, based on the comparison between Figs. 7 and 10. The maximum value of the computed von-Mises stress is now around $37 \mathrm{MPa}$. However, the CPU time has noticeably increased (Table 1). It can be concluded that for an accurate solution, it would be necessary to noticeably reduce the punch speed because of the inertia effects and the propagation of the elastic waves in the elastic punch.

With the use of a punch velocity of $1 \mathrm{~m} / \mathrm{s}$, the contact forces acting on the elastic punch are found almost identical to those acting on the rigid one (Fig. 11), as in the static implicit case.
Furthermore, the CPU times of the different simulations, carried out using dynamic explicit scheme, are summarized in Table 1 (Pentium VI, 2.8 GHz, 2 Go RAM).

The above results show that the full coupling is not necessary regarding the distribution and the intensity of the contact forces. Moreover, if explicit codes are used (which is standard in stamping simulations) very small time steps are required to obtain good stresses in the elastic tools, leading to large and unacceptable CPU times. It can be concluded that in a general 3D stamping simulation, the full coupling between the elasticity of tools and part, involves strong practical difficulties, if explicit code is used:

(i) it would be necessary to use hundreds of thousands or even more elements in the FE model;

(ii) in order to obtain an accurate solution, it is necessary to noticeably reduce the punch speed involving massive and unacceptable computational times.

Based on these difficulties, it is therefore relevant to decouple the simulation of the blank forming and the linear elastic analysis of the tools. Thus, the 3D stress analysis of the tools can be performed separately by exploiting the knowledge of the distribution of the contact forces acting on the rigid tools during the forming operation.

\section{Description of the proposed method}

\subsection{Principle and assumptions}

The contact forces acting on the rigid tools during the forming operation have been found almost identical to those acting on the real standard steel tools (see Section 2). Hence, the stress analysis of tools can be performed using the classical stamping simulation approach by considering rigid tools and by exploiting the knowledge of the distribution of the resulting contact forces. Thus, our procedure involves two separate steps (Fig. 12):

(i) step 1, the stamping simulation is first conducted classically by considering rigid tools, allowing to obtain an estimation of the distribution of the contact forces acting on the rigid tools during the forming operation;

(ii) step 2, the stamping tool (layered or not) is analysed separately by considering its elastic deformation and by applying the distribution of the contact forces computed previously (in step 1) and considered as a static external load.

In the present study, the STAMPACK finite element code [18] and the CATIA V5 finite element module [19] were used to perform the step 1 and step 2, respectively. The reason behind this choice is that STAMPACK and CATIA V5 offer some facilities and advantages to deal with the above procedure in two steps [12].

The above procedure, in two steps, is based on the assumption that the contact forces acting on the rigid tools are almost identical to those acting on the real steel deformable ones. 


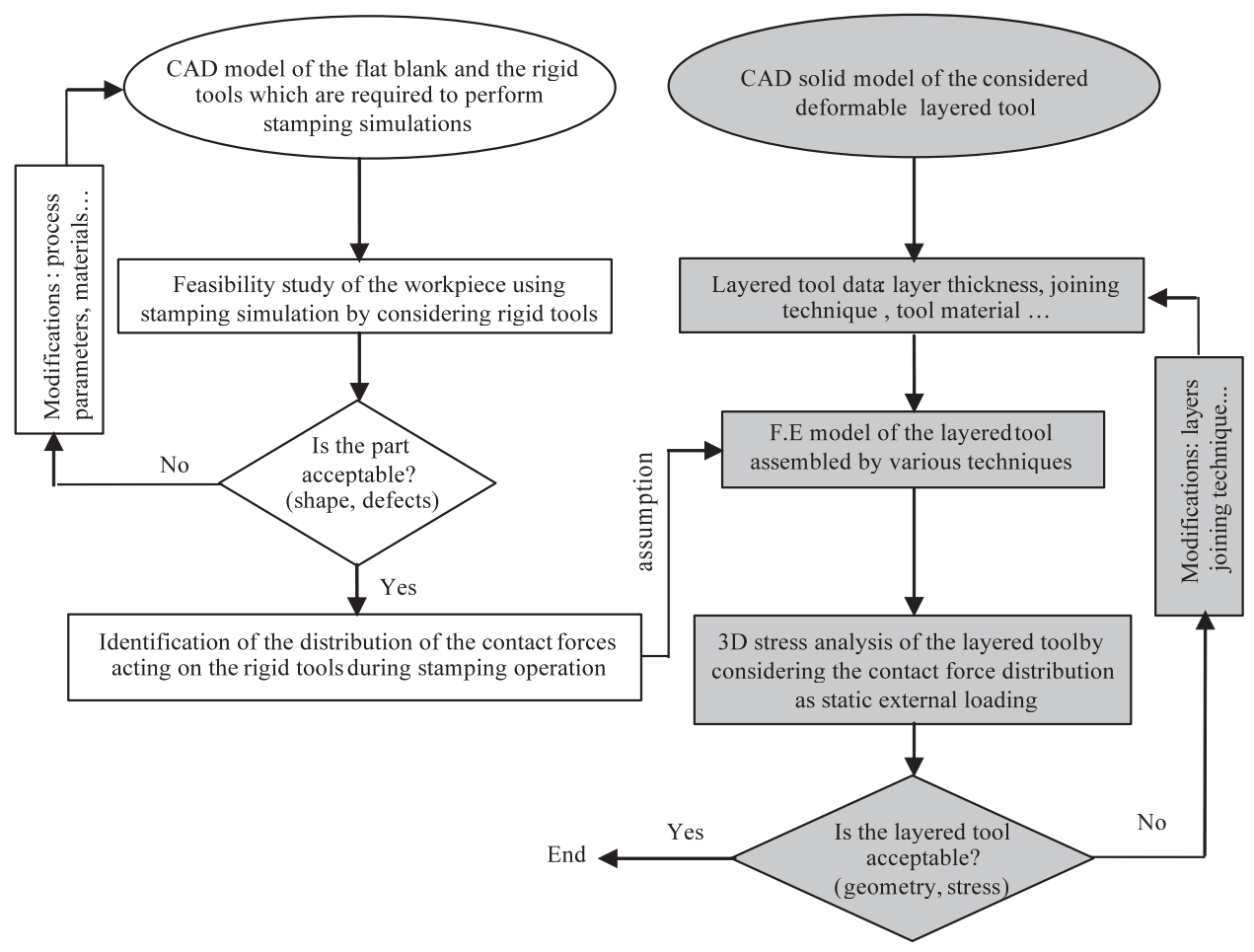

Fig. 12. The flowchart of the proposed procedure in two steps.

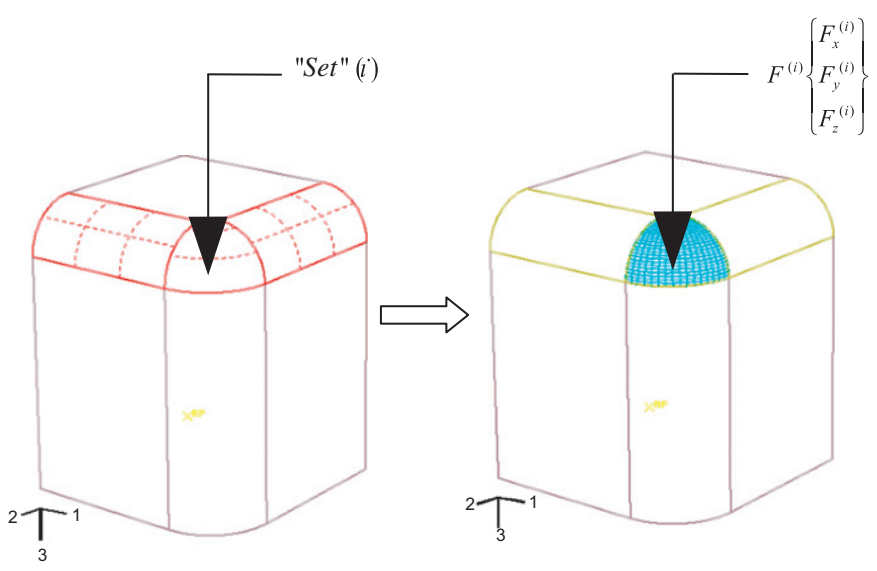

Fig. 13. Schematization of elementary "Sets"/corresponding contact force vector.

\subsection{Estimation of the contact forces}

At the beginning of step 1, the surface of the rigid tool (active tool parts) is divided into small sectors called "Sets" (Fig. 13). For each "Set" $(i)$, the global nodal contact force vector, with its three cartesian components, is automatically computed in STAMPACK and can be expressed as follows:

$$
F^{(i)}=\sum_{j=1}^{n n d} F_{j}^{(i)}
$$

with $F^{(i)}=\left(F_{x}^{(i)}, F_{y}^{(i)}, F_{z}^{(i)}\right)$, where $n n d$ is the number of nodes in "Set" $(i)$.

The third component $F_{z}^{(i)}$ represents the vertical punch reaction force acting on the "Set" $(i)$. Then, the total punch reaction force, denoted $F_{Z}$, can be expressed as follows:

$F_{Z}=\sum_{i=1}^{n s e t} F_{z}^{(i)}$

where nset is the number of sectors (or "Sets") in the active tool parts.

\subsection{Equivalent static external load}

In order to simplify the transfer of the distribution of the contact forces from the rigid tool to the deformable one (layered or not), the elementary force vectors $F^{(i)}$ computed previously, in step 1, for each "Set", are automatically replaced (by considering their three cartesian components) by a system of equivalent static loads $P^{(i)}$, distributed according to the following relation:

$F^{(i)}=\iint_{s} P^{(i)} \mathrm{d} s^{(i)}$,

where $\mathrm{d} s{ }^{(i)}$ is the area of the elementary "Set" number $(i)$.

The above procedure has already been validated in [12] in the context of simple deep-drawing geometries. The obtained results showed that this procedure gives fairly good stress and strain estimations in the tools compared to that obtained in the context of deep-drawing simulation taking into account elastic deformation of tools, using the ABAQUS static implicit code. 


\section{Application to the layered tools: 3D case study}

\subsection{Description of the case study}

A layered stamping punch (Fig. 14) with dimensions: $420 \mathrm{~mm} \times 220 \mathrm{~mm} \times 77 \mathrm{~mm}$, based on the Stratoconception ${ }^{\circledR}$ process, was considered as the example of the application. The layered punch was built by stacking $7 \mathrm{~mm}$ thick of EN DIN 2C45 (NF EN XC48) steel sheets [9], which were directly machined by laser cutting and micro-milling. Several screws were used for the joining of the layers in addition to an epoxy adhesive with thickness of $0.1 \mathrm{~mm}$, which was inserted between layers.

According to the procedure illustrated in Fig. 12, two separate steps of analysis are required to make 3D stress analysis of the tool.

\subsection{Step 1: classical stamping FE analysis}

In the finite element model, a mesh of three-node BST (Belytschko Shell Triangular) shell element was used in the full model of the blank involving 382518 elements, while the other tools (punch, die and blankholder) were assumed rigid. The blankholder force was $50 \mathrm{kN}$, punch stroke was $50 \mathrm{~mm}$. The material data are: isotropic elasto-plastic behaviour with isotropic hardening given by Hollomon's model with the following material constant: $k=522.4 \mathrm{MPa}, n=0.23, E=210 \mathrm{GPa}$, $v=0.3$.

The contact formulation is based on the master-slave contact approach [18]. The tools are considered as the master surfaces and the sheet is the slave surface. The Coulomb friction model was adopted with a frictional ratio $\mu=0.1$ and the interaction between the sheet and the tools is formulated using the finite sliding approach, which allows the separation of the two surfaces during sliding.

First, some results with regard to the feasibility of the blank forming (shape, strain, stress, thickness distribution) were examined [12]. The obtained workpiece (Fig. 15) is qualitatively in agreement with the experimental one, regarding the part shape.

Second, simulations were run in order to obtain an estimation of the distribution of the contact forces acting on the rigid punch during the stamping operation.

Fig. 16 shows the contact pressure distribution on the rigid punch at the end of the forming stage. It can be seen that the contact forces are mainly located along the punch radius (active parts). This result is in good agreement with the literature $[3,12,14,15,17]$. The CPU time was around $10 \mathrm{~h}$ (Pentium VI, $2.8 \mathrm{GHz}, 2$ Go RAM).

\subsection{Step 2: modelling and FE analysis of the punch}

In this second step of simulation, the layered punch was analysed separately from step 1 . As shown in Fig. 17, the punch CAD model was generated in CATIA V5 and sliced into $7 \mathrm{~mm}$ thick elementary layers to be consistent with the real one.

The joining technique consists in 2 plugs $\left(G_{1}\right.$ and $\left.G_{2}\right)$ and 5 screws $\left(S_{1}\right.$ to $\left.S_{5}\right)$, in addition to an epoxy adhesive.

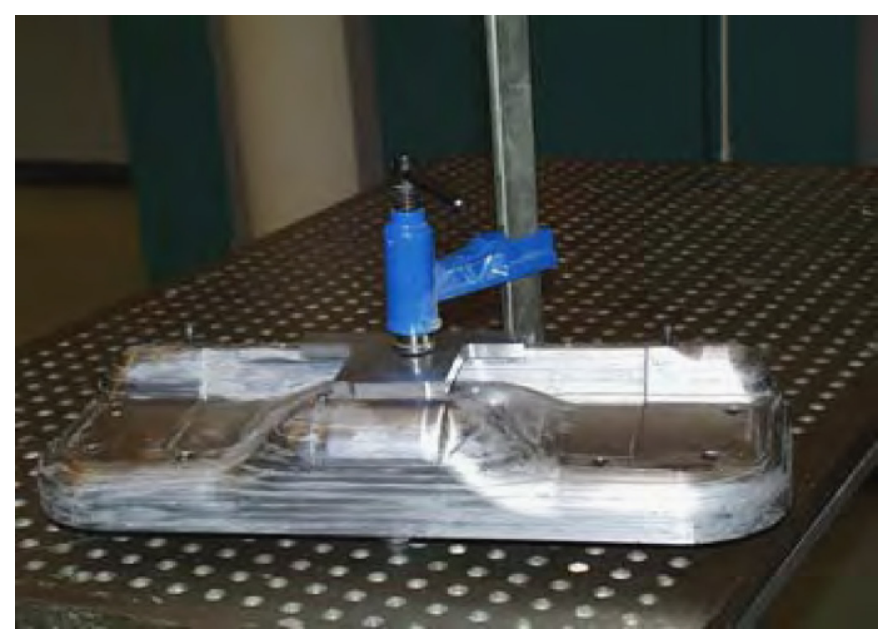

Fig. 14. The studied stamping layered punch (source: CIRTES).

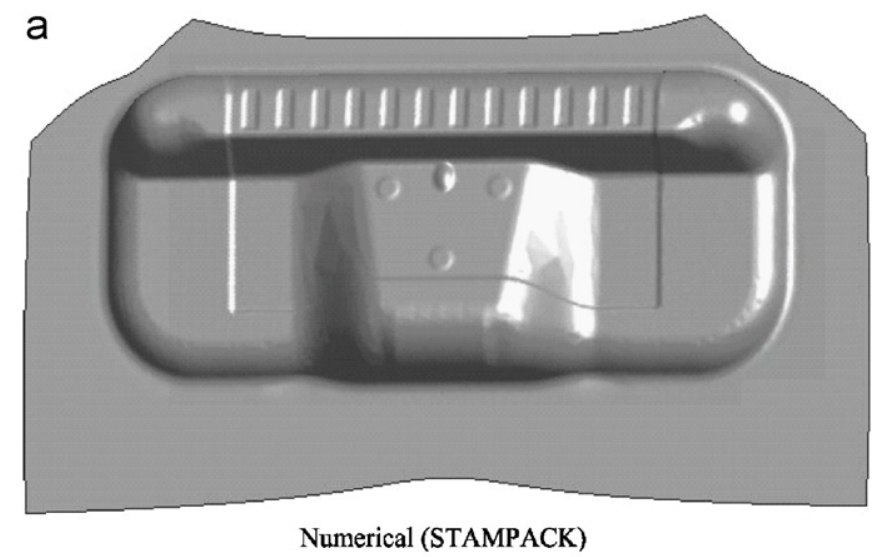

b

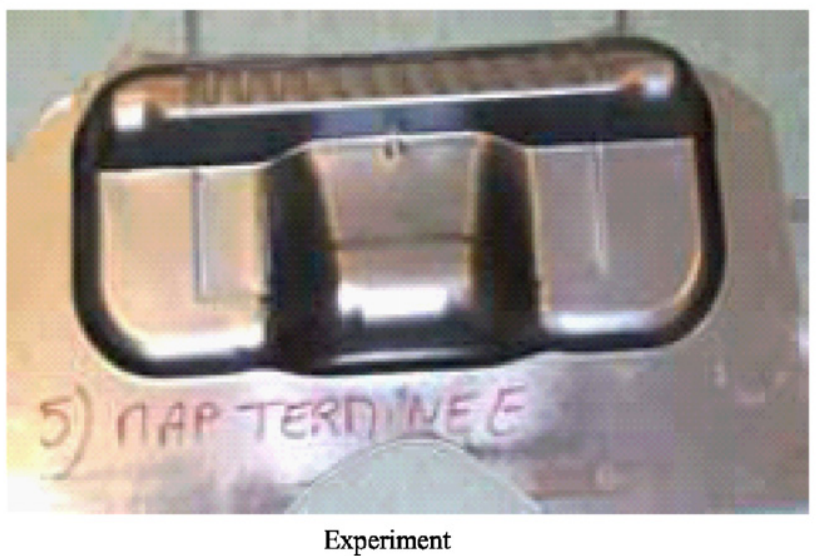

Fig. 15. Workpiece final shape: comparison with experiments.

The finite element model involves 210124 four-nodes tetrahedral elements with a mesh refinement in the vicinity of the screw holes.

The EN DIN 2C45 (NF EN XC48) steel layers are elastic and isotropic with the following properties: $E=210 \mathrm{GPa}, v=0.3$.

The adhesive with thickness of $0.1 \mathrm{~mm}$ was not modelled in detail but each interface between the steel layers is clearly 


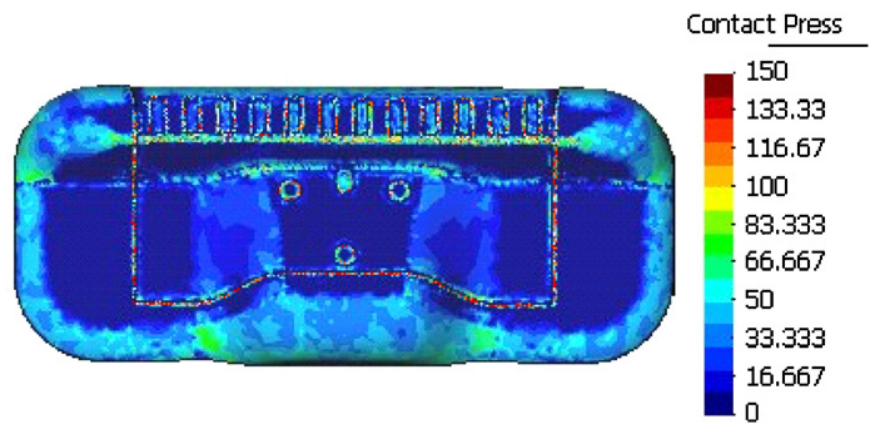

Fig. 16. Contact pressure (MPa) distribution on the rigid punch (STAMPACK).
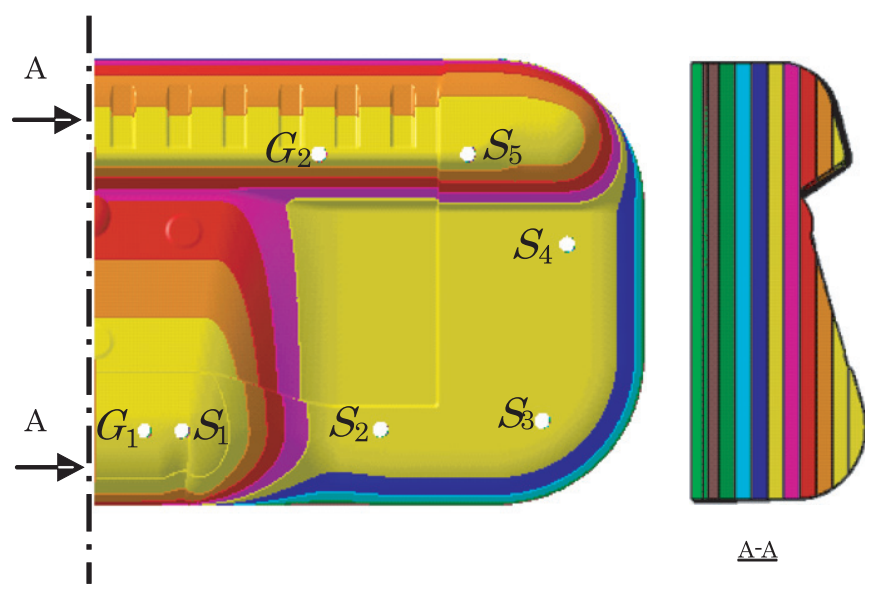

Fig. 17. CAD model of the layered punch (CATIA V5).

identified in the 3D FE model. As a first assumption for this study, the nodes at the interfaces belonging to the layers are tied leading in fact to a continuous medium. Attention is then paid to the post-processing stage to the maximum tensile and shear stresses which are compared to the corresponding admissible yield stresses of the adhesive. If the stress levels are satisfactory, then sliding or separation of the layers is not possible. Of course the role of the adhesive on layers assembled by screws is important as mentioned in [12,20] but its precise evaluation is considered beyond the scope of the present study and should be addressed in a future research paper.

The loading conditions are as follows:

(i) The initial clamping state: this stage is automatically generated in CATIA V5, by assuming minimal clamping force of $6000 \mathrm{~N}$ for each screw.

(ii) The forming load: the distribution of the contact forces, provided by the numerical simulation, in step 1, is automatically imported in CATIA V5 and applied to the layered punch FE model as a static load.

\subsection{Results and discussions}

The stress and strain distributions in the layered punch have already been investigated in [12] and it was found that the joining technique by screws requires more attention and plays

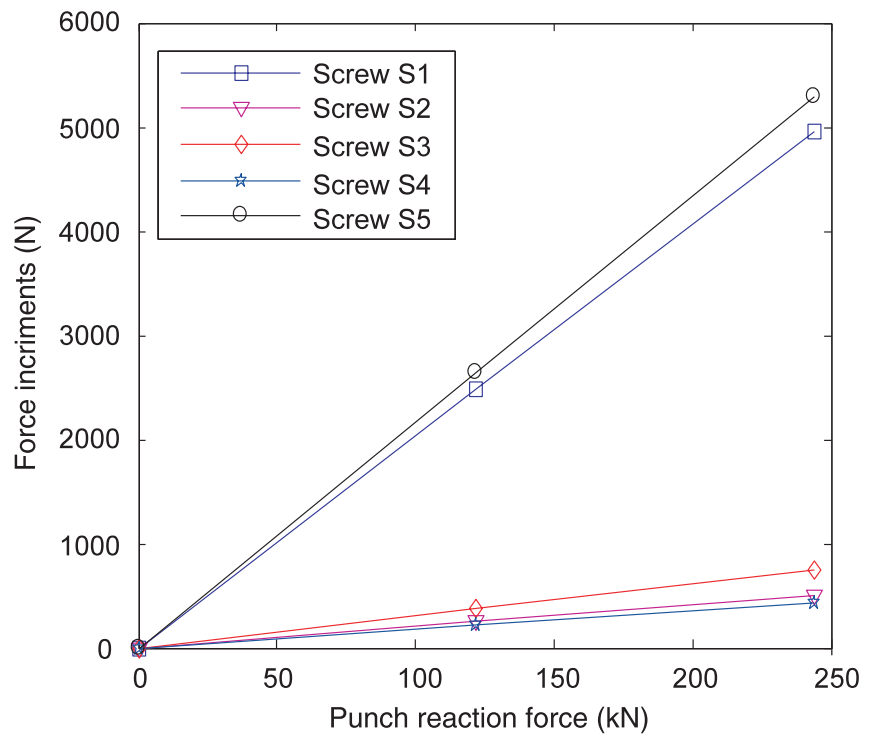

Fig. 18. Increments (variations) in initial axial screw forces as a function of the stamping load (punch reaction force).

an important role in the design decision of layered tools. Thus, we focussed on what happens in the screws, under the forming load.

When the distribution of the contact forces (due to the stamping) is applied to the layered punch, which is joined with an initial clamping force $\left(F_{S}\right)_{i}$, increments (variations) $\Delta F_{S j}$, in the axial screw forces, are produced. Fig. 18 shows the increments in the axial screw clamping forces as a function of the axial forming load $F_{Z}$. It can be seen that the increments $\Delta F_{s j}$ occurring in axial screw forces increase linearly with the increase of the forming load (contact forces). This result is in agreement with the literature [20].

From Fig. 18, it can be seen that the highest values of increments are produced in screws $S_{1}$ and $S_{5}$ (Fig. 17), while the increment values in the other screws are not significant. This can be explained using the theoretical relationship between the increment and the axial forming load, occurring in each screw, which can be expressed as follows [20]:

$\Delta F_{S}=\left[\left(F_{S}\right)_{\mathrm{i}}-\left(F_{S}\right)_{\mathrm{f}}\right]=\frac{K_{t}}{K_{t}+K_{c g}}\left(\frac{K_{c g}^{\prime}}{K_{p t}}\right) \cdot F_{Z}$.

The quantity $\phi=\left(K_{t} /\left(K_{t}+K_{c g}\right)\right)\left(K_{c g}^{\prime} / K_{p t}\right)$, is called the screw load factor.

$K_{t}$ is the spring constant for a screw system and $K_{c g}$ is the compressive spring constant for layers around a screw hole. $K_{c g}^{\prime}$ and $K_{p t}$ are the compressive spring constants defined using the mean displacements produced in the screw holes when the initial clamping force and the stamping load are, respectively, acting. $\left(F_{S}\right)_{\mathrm{i}}$ and $\left(F_{S}\right)_{\mathrm{f}}$ are, respectively, the initial and the final axial screw forces.

The slopes of $\Delta F_{S j}$ (Fig. 18) are independent of the initial clamping force $\left(F_{S}\right)_{\mathrm{i}}$ and can be used in order to obtain the individual screw load factors. 
On the other hand, it is found that the value of $\left(F_{S}\right)_{\mathrm{f}}\left(=\left(F_{S}\right)_{\mathrm{i}}+\right.$ $\left.\Delta F_{S}\right)$, in each screw, decreases because the value of $\Delta F_{S}$ is negative.

In such a screwed joint, the initial prestressed screws should remain in tension under the loading conditions, for a proper strength of the joint. Hence two problems, related to this joining technique, can be identified:

(i) The decrease in the initial clamping force, due to the forming load, is not allowed when the final screw clamping force tends to zero (this can lead to screw loosening).

(ii) The increment occurring in the axial screw clamping force can lead to large force increments in the screws, which can greatly affect the fatigue behaviour (inducing cyclic stress in the screws). The cyclic stress in each screw can be expressed as follows:

$$
\sigma_{\mathrm{cycl}}=\frac{\left[\left(F_{S}\right)_{\mathrm{i}}-\left(F_{S}\right)_{\mathrm{f}}\right]}{2 \cdot A_{S}}=\frac{\Delta F_{S}}{2 \cdot A_{S}},
$$

where $A_{S}$ is the cross section of the screw.

Based on these remarks, it is therefore relevant to reduce the increments occurring in axial screw clamping forces, due to the forming load, in order to improve the strength and the life duration of the joining technique.

\section{Conclusion}

In this paper, a simplified numerical procedure for the $3 \mathrm{D}$ FE analysis of elastic sheet metal stamping tools, in particular those based on rapid prototyping techniques, is proposed and discussed with particular attention to the analysis of layered tools joined by adhesive and screws. The stress analysis procedure is based on the decoupling of the simulation of the blank forming with the elastic analysis of the deformable tools.

The adhesive is not fully considered in the present analysis, but the stress field is particularly analysed at the layer interfaces to check the validity of the assumption of material continuity.

The numerical approach has been applied to the industrial application of a layered punch designed and manufactured using the Stratoconception ${ }^{\circledR}$ system. The following remarks can be mentioned:

(i) The decrease in screw prestresses are highly related to the stamping load and also to the spring constants of the joined layers around the screw holes. It is then advisable to reduce these decreases, as much as possible.

(ii) The initial clamping force must be considered as an important parameter to guarantee minimal tensile force in axial screws when the decrease in axial screw force is large.

(iii) The decrease in axial screw forces can lead to large stress increments (or variations) in the screws, which can greatly affect the fatigue behaviour of screws.

More detailed research work is now in progress towards the improvement of the strength and the life duration of the joining technique by screws. Important optimization issues can be proposed, such as the optimization of the screw positions which should be addressed in a future work.

\section{References}

[1] T. Nakagawa, Advanced in prototype and low volume sheet forming and tooling, J. Mater. Process. Tech. 98 (2000) 244-250.

[2] D.H. Mueller, H. Mueller, Rapid Prototyping Techniques to Manufacture Sheet Metal Forming Tools, ISATA, Dublin, Ireland, 2000.

[3] M. Oudjene, J.-L. Batoz, F. Mercier, L. Penazzi, C. Pelaingre, Mechanical analysis of prototyping tools for sheet metal stamping, in: Proceedings of RPD2004-Advanced Solutions and Development, Marinha Grande, Portugal, October 12-13, 2004.

[4] H. Muller, J. Sladojevic, Rapid tooling approaches for small lot production of sheet metal parts, J. Mater. Process. Tech. 115 (2001) 97 -105 .

[5] D.F. Walczyk, D.H. Hardt, Design and analysis of reconfortable discrete dies for sheet metal forming, J. Manuf. Syst. 17 (6) (1998) 436-454.

[6] D.F. Walczyk, D.H. Hardt, Rapid tooling for sheet metal forming using profiled edge laminations-design principles and demonstration, J. Manuf. Syst. 120 (1998) 746-754.

[7] D.F. Walczyk, D.H. Hardt, A comparison of rapid fabrication methods for sheet metal forming dies, J. Manuf. Syst. 121 (1999) 214-224.

[8] P.M. Dickens, Principles of design for laminated tooling, Int. J. Prod. Res. 35 (N5) (1997) 1349-1357.

[9] C. Abel, L. Velnom, C. Barlier, P. Poirier, FASTOOL et MOLSTRA, Deux projets européens de recherche collaborative en PME (CRAFT) - intégration du procédé de Stratoconception en outillage rapide direct pour l'injection, l'emboutissage et la fonderie sous pression, Micad 2003, Paris 1-3 avril 2003.

[10] B. Wadman, Fluid cell forming tools produced by different rapid prototyping methods, in: Proceedings of the 22th International Deep Drawing Research Group Congress, Bled, Slovenia, 2003, pp. 205-214.

[11] M. Oudjene, F. Mercier, L. Penazzi, J.-L. Batoz, 3D finite element modeling and analysis of the laminated tooling behaviour in sheet metal stamping process, in: Proceedings of the 24th International Deep Drawing Research Group Congress, Besanćon, France, June 20-22, 2005.

[12] M. Oudjene, Modélisation et optimisation du comportement mécanique des outils d'emboutissage stratifiés précontraints par vissage, Ph.D. Thesis, Institut National Polytechnique de Lorraine, Nancy, France, 2005.

[13] T. Pepelnjak, K. Kuzman, Adaptable tooling sets for metal forming of geometrically similar products, J. Mater. Process. Tech. 80-81 (1998) 413-420.

[14] J. Dankert, Reduction of the residual stresses in a deep-drawing cup by modifying the draw die profile, Ann. CIRP 44/1/ (1995).

[15] F.F. Damborg, M.R. Jensen, K.B. Nielsen, J. Dankert, Optimization of the draw die profile with regard to wear using the FEM, in: Proceedings of the 19th International Deep Drawing Research Group Congress, Eger, June 10-14, 1996.

[16] A. Makinouchi, E. Nakamachi, E. Onate, R.H. Wagoner (Eds.), Proceedings of the Second International Conference on Numerical Simulation of 3-D Sheet Metal Forming Processes-Verification of Simulation with Experiments (Numisheet'2002), Isehara, Japan, 31 August-2 September, 2002.

[17] M. Burlat, Analyse Mécanique et Tribologique de l'emboutissage: application aux outils fabriqués par combinaison de différents matériaux, Ph.D. Thesis, Institut National des Sciences Appliquées de Lyon, 1998.

[18] Quantech ATZ, Stampack user guide-version 5.6, Quantech edition, Edificio Nexus, Gran Capitán, 2-4, 08034, Barcelona, Spain, 2004.

[19] CATIA V5 R14 (2005) user guide, documents online.

[20] M. Yoneno, T. Sawa, T. Ishihara, The strength of joints combining adhesives with blolts (case where adherends are pipe flanges of which the interfaces are bonded partially), JSME Int. J. Series A 42 (N1) (1999) 126-134. 